\title{
Geospatial Development Using GIS Smart Planning
}

\author{
Ana Cornelia BADEA ${ }^{1 *}$ and Gheorghe BADEA ${ }^{1,2}$ \\ ${ }^{1}$ Faculty of Geodesy, Technical University of Civil Engineering, 122-124 Lacul Tei Blvd., $2^{\text {nd }}$ District, \\ 020396, Bucharest, Romania \\ ${ }^{2}$ Faculty of Urban Planning, "Ion Mincu” University of Architecture and Urbanism, 18-20 Academiei St, \\ 010014, Bucharest, Romania \\ *corresponding author: ana.badea@utcb.ro
}

BulletinUASVM Horticulture 76(2) / 2019

Print ISSN 1843-5254, Electronic ISSN 1843-5394

DOI:10.15835/buasvmcn-hort: 2019.0034

\begin{abstract}
Zoning is the most effective public tool for controlling land use, reflecting the spatial separation of urban land use incompatibilities and influencing, consequently, the physical economic and social structure of cities. In this paper we want to emphasize the possibilities and benefits of using dedicated GIS solutions for geospatial planning, integrating 3D and 2D data. At present, GIS provides complex tools dedicated to spatial planning analyzes, of which we chose a new Esri solution. The results consist of setting up the appropriate planning parameters, correlated with the local urban planning regulation and applying a coherent workflow in ArcGIS Urban for the GIS analysis of the reconfiguration of an area in Bucharest, as example. We have demonstrated the advantages of using intelligent spatial planning products to verify the conditions provided in the local urban planning regulations. We highlighted the possibility to highlight by analyzing certain evolving indicators, such as population, degree of employability, etc. Obviously, as more relevant Romanian statistical data will be available in the online environment, such analyzes may increase as complexity level.
\end{abstract}

Keywords: ArcGIS Urban, geospatial, GIS, smart city, smart planning

\section{Introduction}

The state, through the public authorities, has the right and the duty to insure, through the activity of urban and spatial planning, conditions for sustainable development and respect for the general interest, according to the law (Law no. $350 / 2001$ ).

Smart cities have the key focus on sustainability and for smart urbanization GIS and related technologies should be used, having the advantages of time-saving and enhance quality of decision-making. Land suitability analysis can be made easer using the existing land use plan and its database in GIS, facilitating to find a more efficient proposed land use.

According with Anthopoulos and Vakali (2012), smart cities are emerging fast and they introduce new practices and services which highly impact policy making and planning, while they co-exist with urban facilities. Urban planning provisions are created based on the European Regional Cohesion Policy, being associated with smart city's architecture layers. The strategies, policies and programs of sustainable development in territorial profile are is based on the Strategy of territorial development of Romania (Law no. $350 / 2001)$.

GIS possibilities are used for devising of an area in a optimizing and smarter way but in most of the developing nations its application is limited to scale in urban management, having the capacity to geocode these variables and stimulate for planning, management and development of a smart city. GIS based urbanization policy can lead to broad allocation of land for future development and delineation of areas for future urbanization 
(https:// nosplan.org/uncategorized/applicationof-gis-in-smart-cities/).

In Romania there have been changes to the law of urban planning that have determined the real estate investors to follow the urban indicators, for example a difference of CUT (coefficient of land use) can mean a significant value in money when evaluating a land.

The major problems are mainly due to the legal situation of the land, for example, there may be problems related to litigation or real estate claims.

The aspects regarding the real estate title are related to the cadastral-legal sphere, and the urban issues involve aspects of the proper application of the legal regulations, being actually at the intersection between the technical and legal notions. It was not yet sufficiently recognized that the real value of real estate is strictly linked to a correct urban planning regime.

One point that caused long disputes between local authorities and litigation against the investor was the adoption of zoning urban plans (PUZ) by the authorities (in Bucharest the fight for the PUZ approval took place between district councils and the General Council of the Bucharest City Hall) (Alexa, 2011).

Zoning is a very efficient public instrument for controlling land use, reflecting the spatial separation of urban land use incompatibilities and influencing, consequently, the physical economic and social structure of cities, areas with specific uses of the land, which describe the intensities of use (ex. individual or collective residential areas), types of commercial, industrial activities etc.

The main specific purposes of zoning are the following: separation of land use types within administrative boundaries; preventing the irrational occupation of agricultural land by introducing in the urban area some lands without analyzing the real demand for urban land; avoiding the appearance of some agglomerations by establishing and registering on the urban plans the maximum allowable densities; ensuring the safety conditions of the population in case of natural calamities (landslides, fire, floods, earthquakes), or in the case of uncontrollable panic of the population; ensuring compliance with the conditions of natural lighting and ventilation of urban areas; ensuring the land for future urban development by types of functions; ensuring the supply of land for temporary constructions requested by unforeseen events (natural disasters).

According to Bydłosz et al. (2018), the land and building cadastre is a very important element of the spatial information infrastructure, on the basis of which various analyses can be carried out and it is assumed that the property cadastre database should contain sufficient data to carry out procedures aimed at sustainable development. It is possible to define UML classes representing spatial planning objects, being strongly dependent on cadastral data.

Spatial planning/zoning with legal implications is one of the topics that are planned under the potential conceptual model extensions of ISO 19152 (https://wiki.tudelft.nl/bin/view/ Research/ISO19152/WorkshopAgenda2017). One of the application schema, technical models and encodings (for schema and data) topics for LADM revision is CityGML. Land Use module contains areas that reflect different land uses, such as urban, agricultural, etc.

European regional planning set of frameworks are containing studies and drawings that need to determine (Anthopoulos and Vakali, 2012): Demographic distribution linked with the Capacity dimension; Land uses that meet the Quality and the History and Landscape dimensions; Transportation and other utility infrastructures that align to Capacity dimension; Forests and parks that concern both the Quality and the Viability Timeline dimensions; The environmental protection framework that contributes to the Quality dimension; The authorities that monitor and evaluate the planning rules that meet all of the framework's dimensions.

3D city models are instrumental in planning tasks including participatory, strategic, and statutory planning(Agius etal.,2018). If the content is partly three-dimensional, it may significantly facilitate decision-making related to development processes. An integration of the 3D cadastre and 3D spatial planning should to be appreciated by the professionals working with urban planning as well as architectural and constructional design (https://wiki.tudelft.nl/bin/view/Research/ IS019152/WorkshopAgenda2017).

In present, land registry and planned land use information are today not yet integrated: there are not based on same conceptual model and it is not 


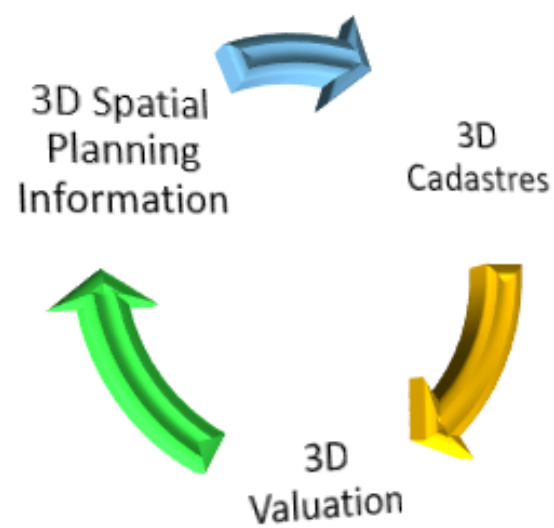

Figure 1. Concept of 3DGI (Oosterom, 2019)

possible to be used together (Oosterom, 2019). It is considered (Agius et al., 2018) that in the last decades the urban entities including buildings and infrastructures are increasingly complex, due to the adoption of more robust technologies such as the use of 3D graphics to envisage the current and future impacts of urban developments.

One method used to construct a 3D city model is to extrude building footprints to obtain polyhedron representing buildings, a wellknown method, easier to implement. If the 2D topological relationships between the footprints are not taken into account, the resulting 3D city models are not necessarily be topologically consistent, meaning that the primitives shared by 3D buildings will be duplicated and/or intersect each other (Ledoux and Meijers, 2011). The RRR (Rights-Restrictions-Responsibilities) approach is very important taking into account the the indoor environments of buildings information that are very rich of Rights for individuals or groups of people. The representation of these Rights are going to improve the use of these environments and the different types of environments require a better understanding of the relationship between the indoor spaces and the users according to the Rights, Restrictions, and Responsibilities of those environments. By comparison with INTERLIS 2 (Badea and Badea, 2006) and according with Oosterom (2019), INTERLIS 3 is under development and it is going soon to be proposed as international standard. This solution offers the automated quality control of the data, data models, a long-term availability based on archiving data, and interoperability between (geographic) information systems, being system independent.
It is proposed by Oosterom (2019) a data structure of LADM-v2 that could be developed as a Core Information Model for the Smart City 3DGI concept: 3D Cadastres, 3D Valuation and 3D Spatial Planning Information (Fig. 1).

\section{Materials and methods}

Over time planners were a bit reluctant (Agius et al., 2018) to use 3D tools because of the complexity with regard to data integration and the ability to easily model an environment and there are needed the appropriate tools to assist planners in decision-making for broad planning task. The case study involves notions as POT (percentage of land occupation), CUT (coefficient of land use) or UTR (territorial unit of reference). City charters today say very little about how municipalities and their partners can and should collect, analyze and use data (Townsend, 2017).

The Local Urban Planning Regulation (RLU) is a PUG (General Urban Plan) related document, describing the restrictions and permissions in the areas drawn on the PUG boundaries. The areas drawn in the PUG are called Territorial Units of Reference (UTR). These areas can be located in smaller or larger areas depending on the homogeneity of land, buildings, relief, landscape, history, plot structure in these areas, etc.

There is not always a precise and correct classification of the land in a certain zoning/UTR (Alexa, 2011), and an unclear classification leads to errors regarding the allowed destination of the development projects, as well as on all the parameters applicable to the property.

The study area is located in Bucharest, Romania. In this case study were integrated on- 


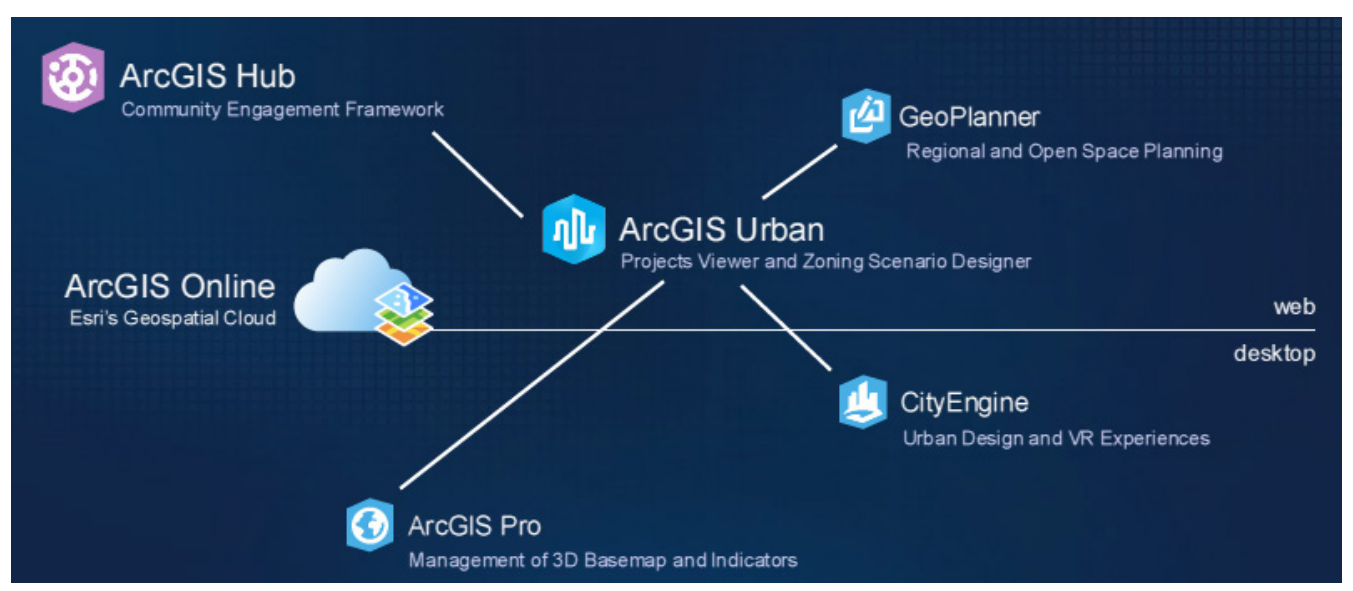

Figure 2. ArcGIS Urban connected with the other Esri software solutions (Staehli and Patrick, 2019)

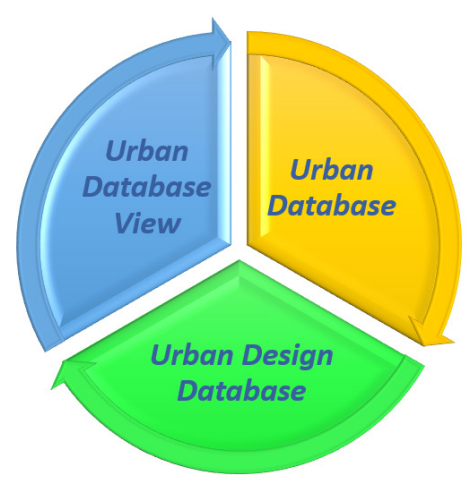

Figure 3. Specific databases in Esri ArcGIS Urban (adapted from https://doc.arcgis.com)

line 3D data (Badea et al., 2018), as well as data about Bucharest territorial reference units (UTR), extracted from the general urban plan. Setting up the zoning types properties were made in compliance with the general urban planning regulations of the Bucharest municipality.

It is used a new Esri software environment, ArcGIS Urban, specially developed for urban planning (Fig. 2).

In ArcGIS Urban can be integrated different datasets in the purpose of obtaining a complex result. (Badea et al., 2015) The software is currently running in beta version, with room for improving the editing, settings related to units of measurement, etc. Three specific databases that can be considered are emphasized in Figure 3.

The data are managed using the feature layers highlighted in Figure 4. In Figure 5 are emphasized the data types and in the Figure 6 the database tables.
Regarding the data integration and management, the existing conditions for parcels, zoning, and overlays, projects and plans that have the facility to be made public can be organized in the Urban Database. In this database exists the writing access to the database granted internally, having the layers and tables that can be edited by members of the organization with the appropriate permission.

The design scenarios with parcels, zoning, and overlays being edited and evaluated based on the capacity indicators. All of these indicators are integrated in the Urban Design Database. The access regarding writing and reading to the database is granted internally and the layers and tables can be edited by members of the organization with the appropriate permission. A synchronized copy of the Urban Database and shared with everyone is Urban Database View. This database is developed only for viewing, showing all changes on the Urban Databas 


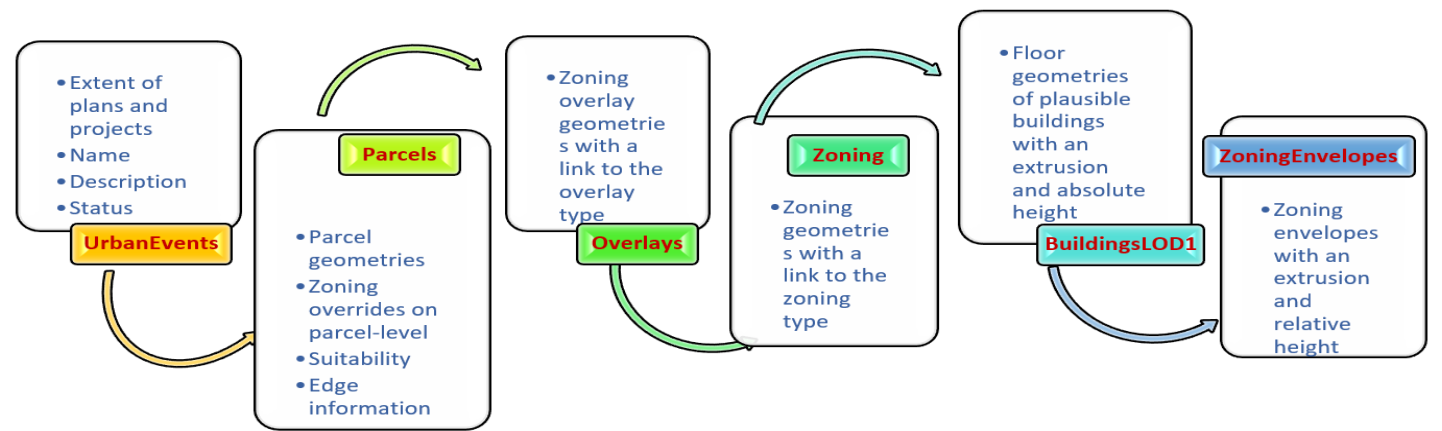

Figure 4. Managing data in ArcGIS Urban Database using Feature Layers

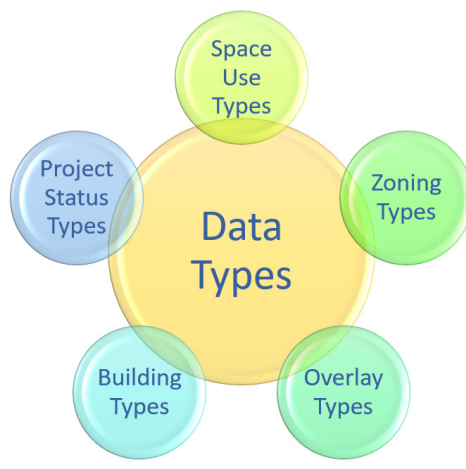

Figure 5. Data types defined and used in ArcGIS Urban

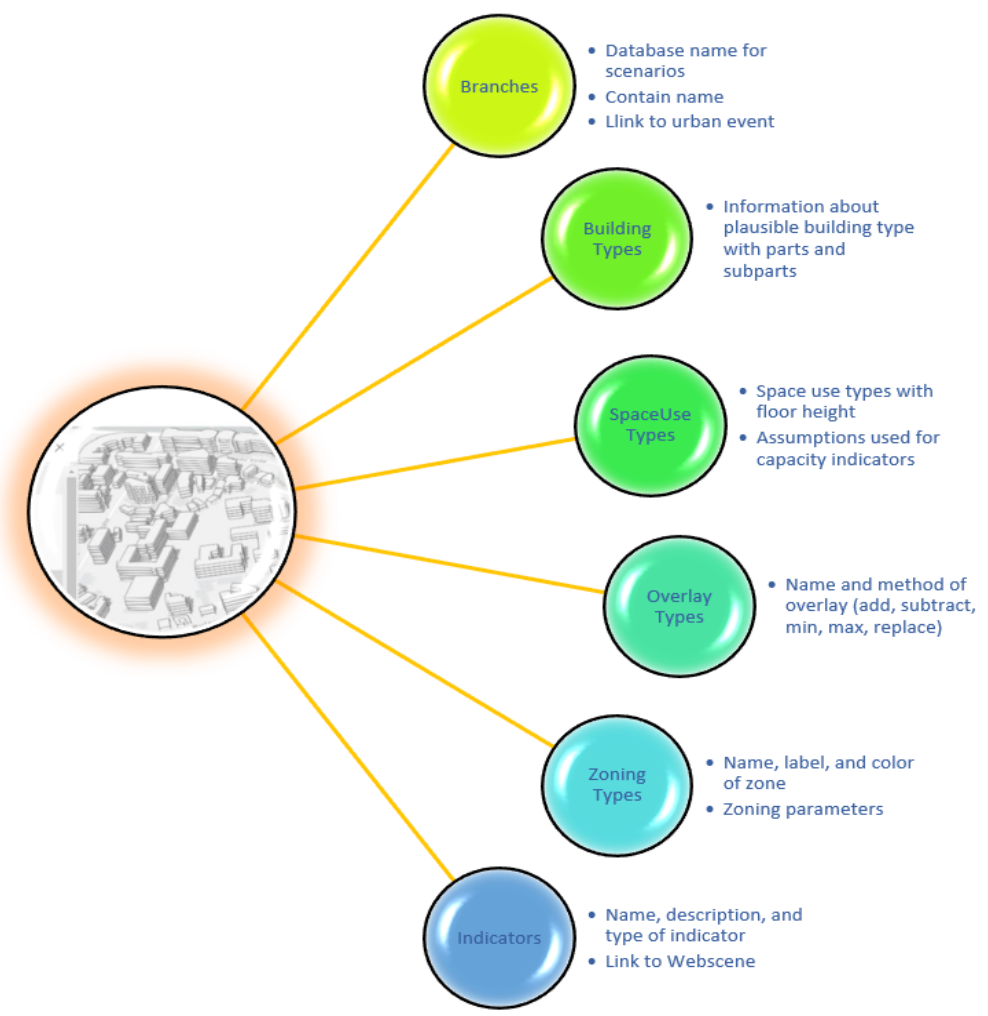

Figure 6. Managing data in dedicated tables 


\section{Results and discussions}

In the project area (Fig. 7 and 8), can be found the L (living zone) category and L1 sub-area (subzone of individual and small collective houses with maximum $\mathrm{P}+2$ floors).

In Figure 9 is highlighted the workflow in ArcGIS Urban. If there was no integrated application, it would have taken considerable effort to create the workflow using a feature and geoprocessing functions chain (Badea and Badea, 2013).

The first zone is defined as L1a, that is to say small and individual dwellings with maximum
$\mathrm{P}+2$ floors outside the protection perimeters, as follows: $\mathrm{H} \max =\mathrm{P}+2(+\mathrm{M}), \mathrm{POT}=45 \%$, CUT $=0.9$ $-\mathrm{P}+1 ; 1,3-\mathrm{P}+2$. In the case of sloping roofs at 45 degrees, the attic is allowed (http://www4.pmb. ro/wwwt/pug/pugs/TAB2001X.htm).

Also in the area there is a subzone L4 (subzone of high collective housing with $\mathrm{P}+5-\mathrm{P}+10$ floors, located predominantly in residential assemblies), and the buildings are part of L4a - subzone of high floor buildings $\mathrm{P}+5-10$ located predominantly in residential assemblies, outside of the protected area. $\mathrm{H}$ max is according with PUZ, maximum POT

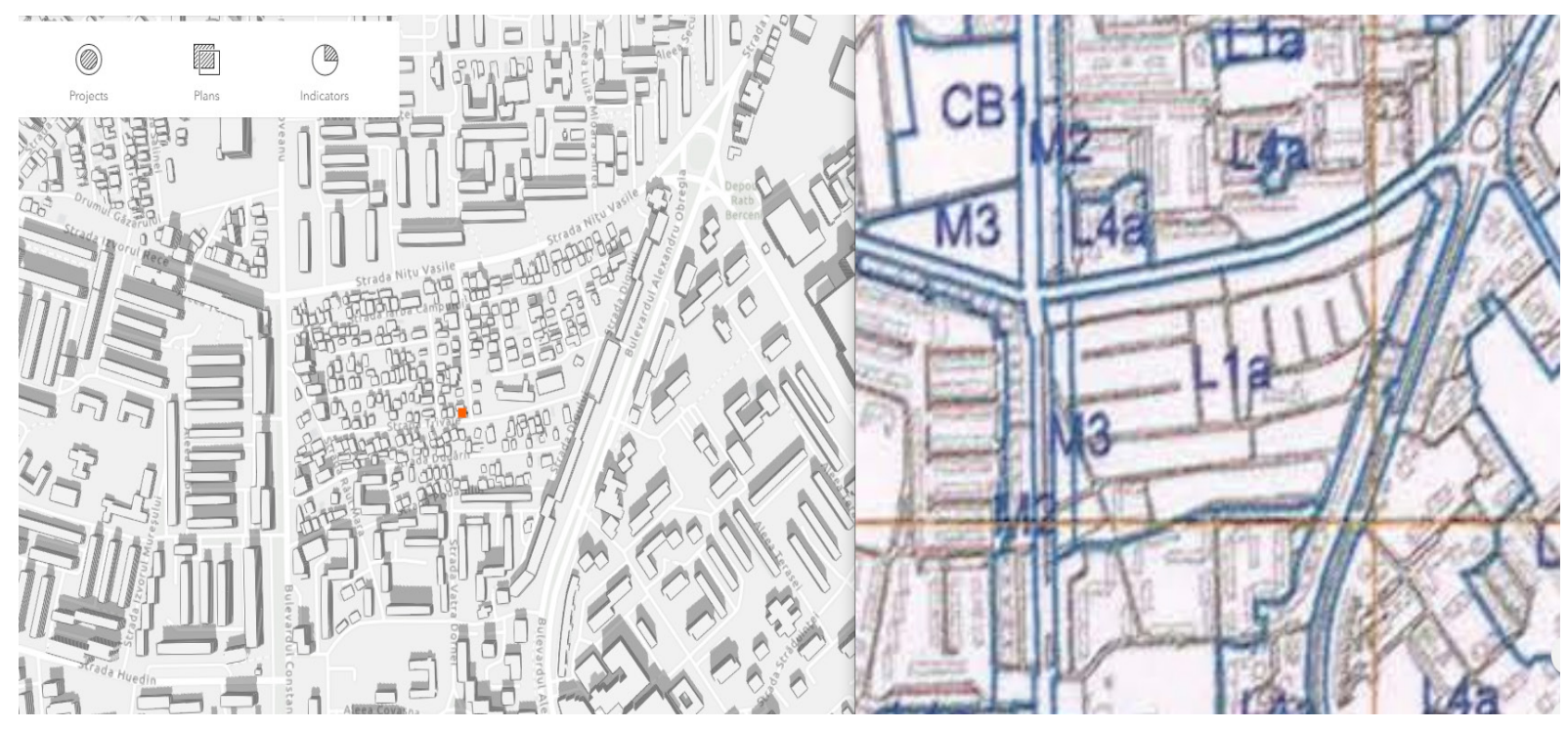

Figure 7. Study area in 2D view in ArcGIS Urban and UTR (http://www.pmb.ro/servicii/urbanism/pug/docs/planul_UTR.pdf)
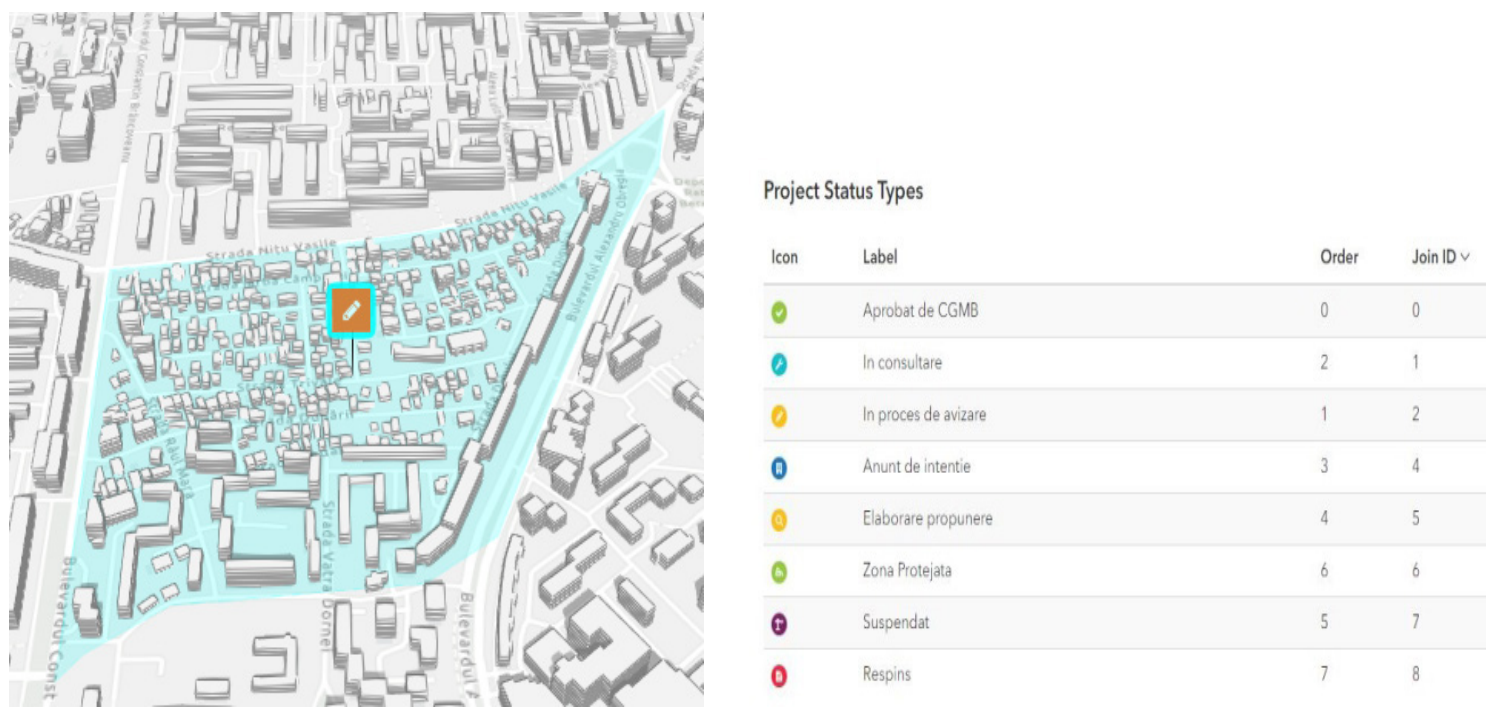

Figure 8. Model of study area in 3D view in ArcGIS Urban and defined project status types 


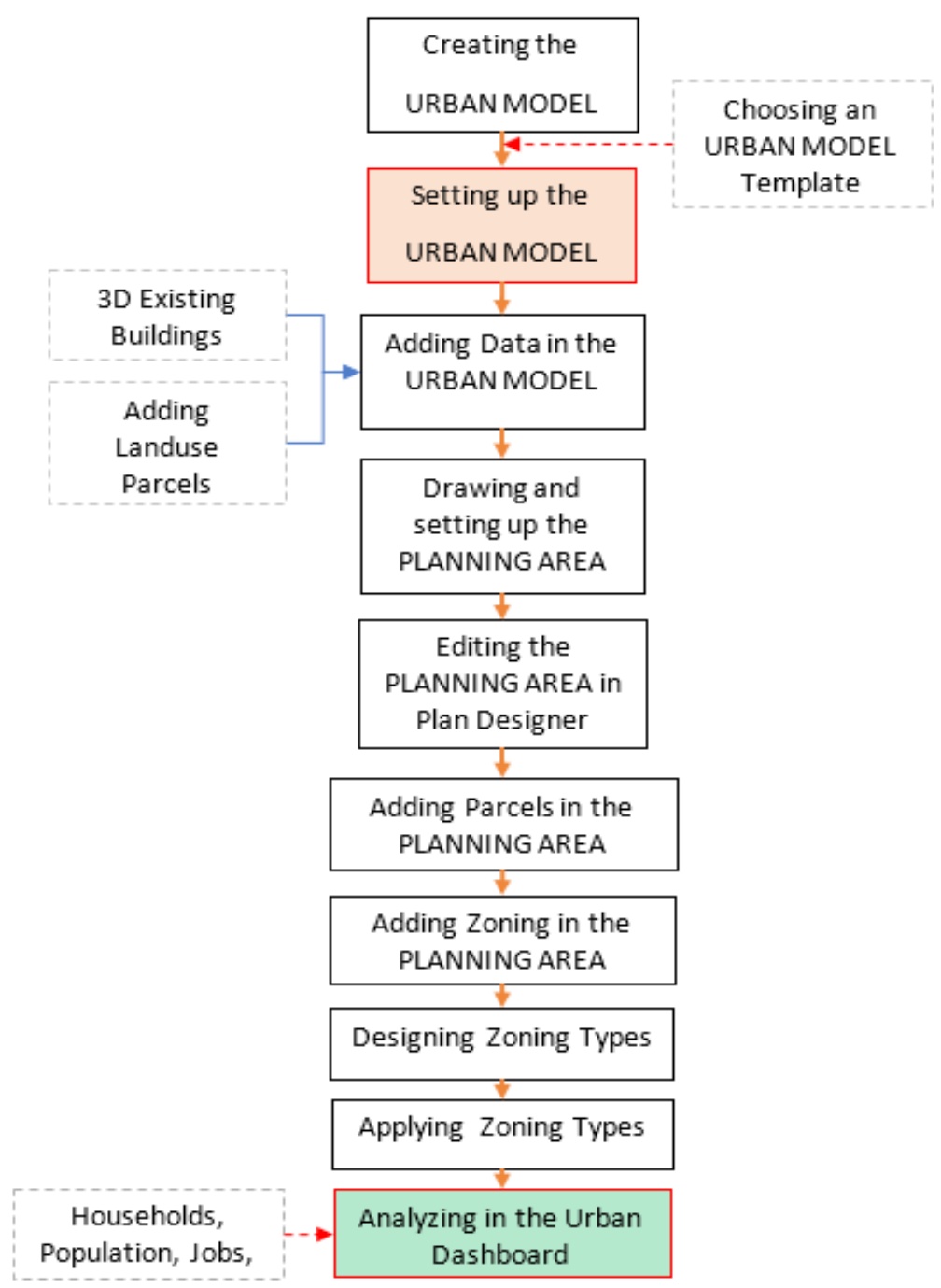

Figure 9. Workflow in ArcGIS Urban

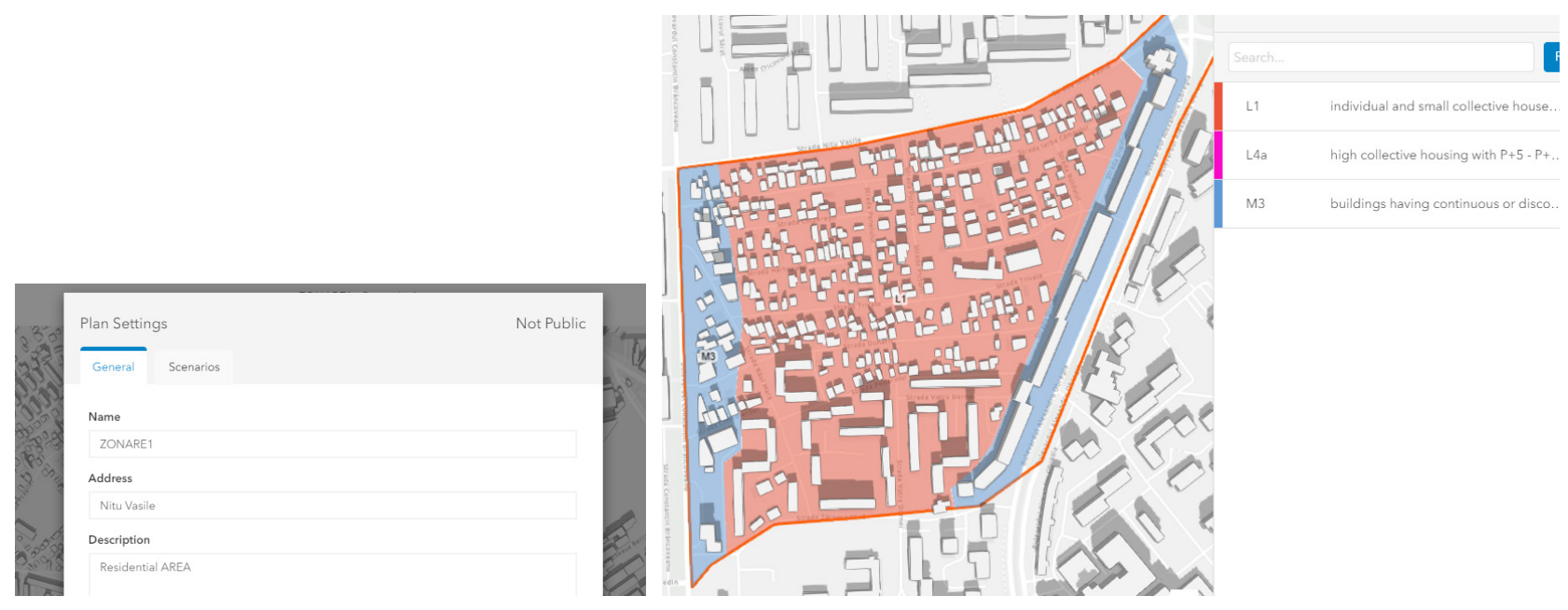

Figure 10. Setting the zoning and parameters according with Local Regulation of Urban Planning - Municipality of Bucharest 


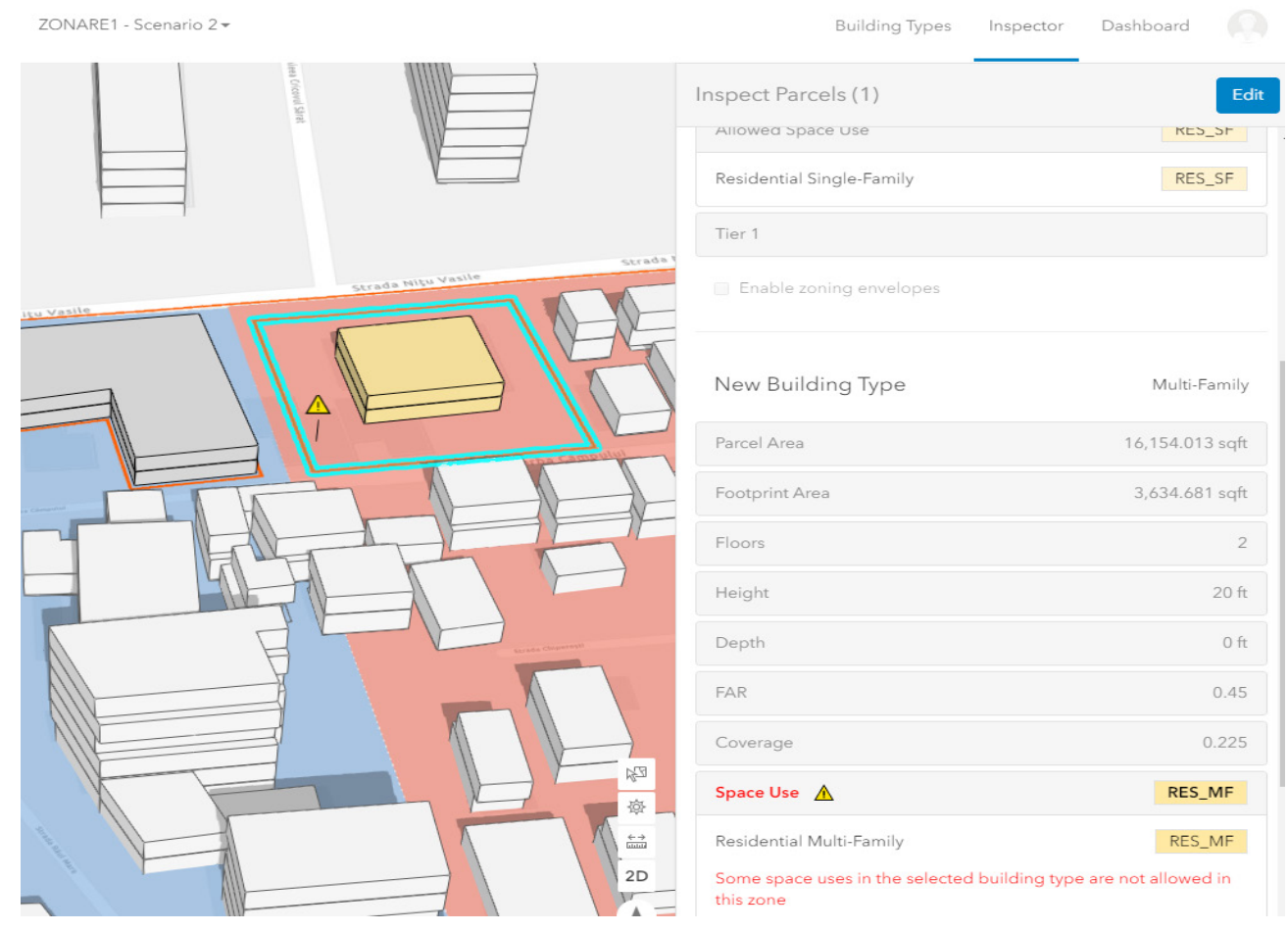

Figure 11. Identifying cases of contradictions between the zoning restrictions and the proposed building

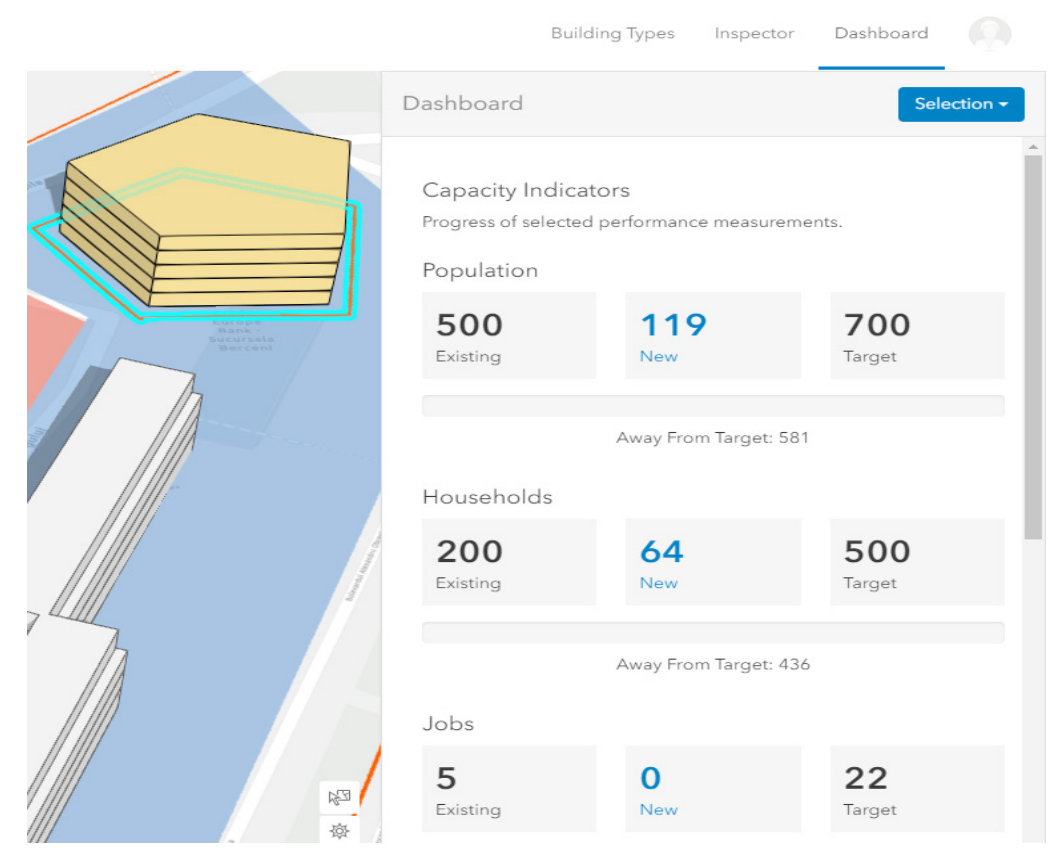

Figure 12. Analyzing the Capacity Indicators

Analyzes were performed regarding the Capacity Indicators (Fig. 8) and the building space use (Fig. 13). 


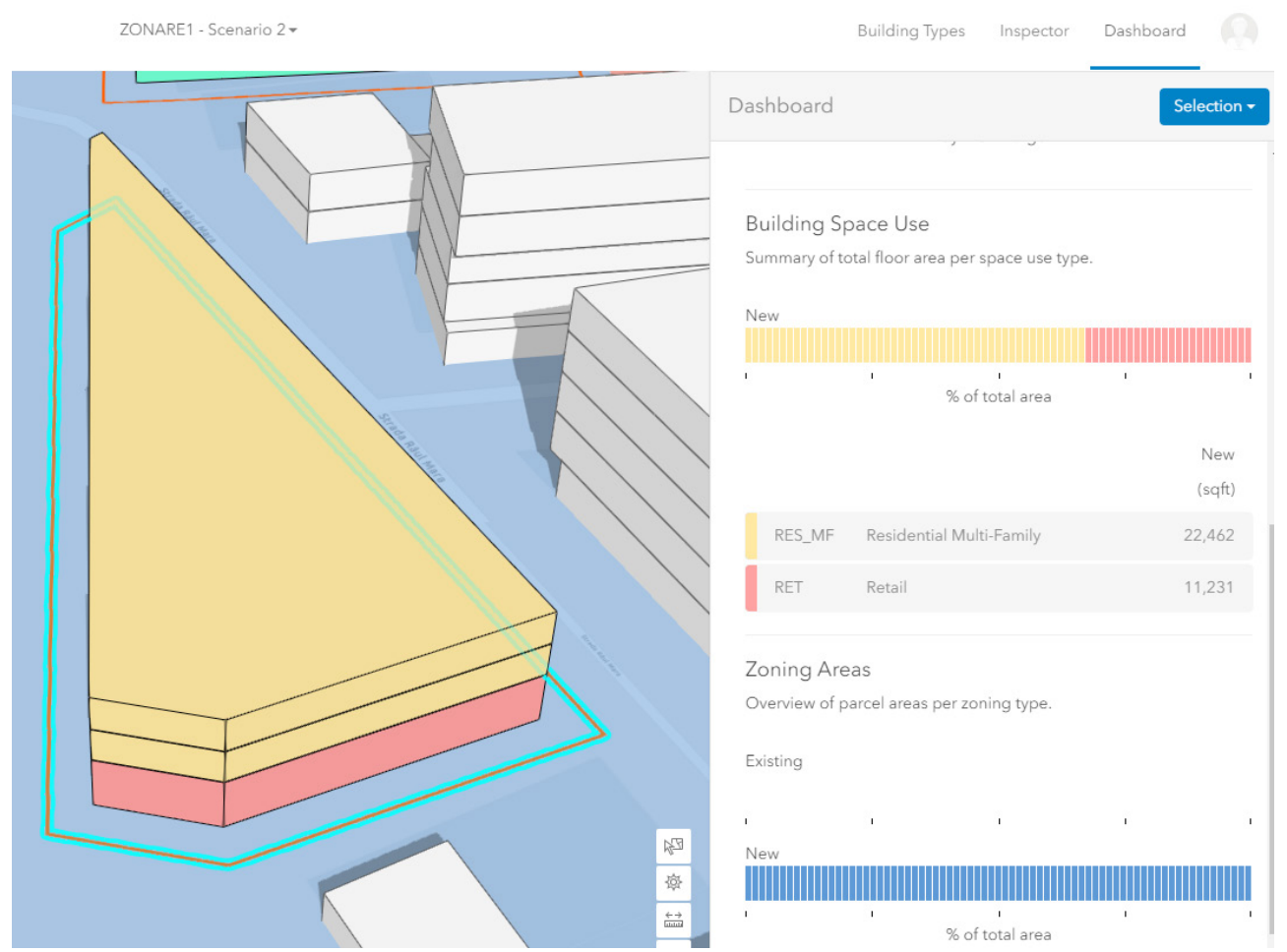

Figure 13. Analyzing the building space use

is $20 \%$ up to $45 \%$ (with maintained lot entries), maximum CUT is 1,4 up to 1,3 (with maintained lot entries).

The third type of zone is M (mixed zone) with M3 subzone (mixed sub-area with buildings having continuous or discontinuous construction and maximum heights of $\mathrm{P}+4$ levels). In this case $\mathrm{H} \max =\mathrm{H}+\mathrm{D}$, maximum $\mathrm{POT}=60 \%$, maximum CUT $=2.5$. In M3 it exists the possibility of covering the rest of the land in proportion of $75 \%$ with buildings with maximum 2 levels ( 8 meters), conditionally one or two levels could be additionally added.

All of these setting parameters can be defined in the software (Fig. 10). The parameters set for zoning, plots, associated buildings will act as useful constraints at the time of planning (Fig. 11), all the inconsistencies being highlighted and explained (Fig. 12).

\section{Conclusion}

This study sets out with the aim of emphasizing the workflow of tools for statutory planning activities through developing a gdb structure and process to use 2D GIS information to model and visualize the 3D built form. A smart city plan means that regulatory and policy reforms are used to find new ways for the planning and zoning rules to be subjected to public interest tests to ensure that the benefits of restrictions to the community outweigh the costs.

The 3D visualization of the urban planning in the developed study could reduce ambiguity amongst stakeholders, leading to minimize disputes, saving time and costs for the state and development industry, as well as providing assurance for the community. The main advantages of this workflow are the following: the development projects can be visualized, tracked and reviewed throughout the entire life cycle, the creation and sharing of zoning are made directly in web browser (3D and 2D) and the performance indicators can be disseminated to the interested parties.

3D urban planning can be designed, developed, verified and readily shared online through ArcGIS Urban. In the future there are needed more effort to validate the geometrical 3D objects for accurate measurement of building height and setbacks. 


\section{References}

1. Agius T, Sabri S, Kalantari M (2018). Three-Dimensional Rule-Based City Modelling to Support Urban Redevelopment Process, International Journal of GeoInformation, ISPRS Int. J. Geo-Inf. 7, 413.

2. Alexa I (2011). Investitorii imobiliari, față în faţă cu PUZ, POT, CUT şi UTR, https://www.zf.ro/business-construct/ investitorii-imobiliari-fata-in-fata-cu-puz-pot-cut-siutr-8196621.

3. Anthopoulos LG, Vakali A (2012). Urban Planning and Smart Cities: Interrelations and Reciprocities. In: Álvarez $\mathrm{F}$ et al. (eds) The Future Internet. FIA 2012. Lecture Notes in Computer Science, vol 7281. Springer, Berlin, Heidelberg.

4. Badea AC, Badea G (2006). New Developments in Data Exchange between Land Information Systems - language INTERLIS 2, Scientific Bulletin of UTCB, ISSN - 1224 628X, 1: 24-33.

5. Badea AC, Badea G (2013). The Advantages of Creating Compound GIS Functions for Automated Workflow, 13th International Multidisciplinary Scientific Geoconference SGEM 2013, Informatics, Geoinformatics and Remote Sensing, Conference Proceedings, Section Cartography and GIS, ISBN 978-954-91818-9-0, ISSN 1314-2704, 1: $943-949$.

6. Badea AC, Badea G, Vasilca D, Iliescu-Cremeneanu A, Badea D (2018). BIM, GIS and CAD (astre) under the Current Challenges, DOI: 10.5593/sgem2018/2.3/S11.042.

7. Badea G, Badea AC, David V (2015). An approach for image processing and advantages of using in GIS, 15th International Multidisciplinary Scientific GeoConference SGEM, STEF92 Technology, 2: 721-728.

8. Bydłosz J, Bieda A, Parzych P (2018). The Implementation of Spatial Planning Objects in a 3D Cadastral Model,
International Journal of Geo-Information, ISPRS Int. J. Geo-Inf., 7, 153.

9. Ledoux H, Meijers M (2011). Topologically consistent 3D city models obtained by extrusion, International Journal of Geographical Information Science, DOI: 10.1080/13658811003623277, Source: DBLP.

10. Oosterom van P (2019). LADM-v2 as Core Information Model for the Smart City 3DGI: 3D Cadastres, 3D Valuation and 3D Spatial Planning Information, 3DGI2019, Campus FHNW, Muttenz, Switzerland, http://www.3dgi. ch/3dgi2019/slides/KN_2_Oosterom_LADMv2.pdf.

11. Staehli L, Patrick B (2019). ArcGIS Urban, https:// proceedings.esri.com (last accessed on 9 September 2019).

12. Townsend A (2017). Smart Cities: What Do We Need to Know to Plan and Design Them Better? https:// medium.com/@anthonymobile/smart-cities-what-dowe-need-to-know-to-plan-and-design-them-betterb6d05e736ea1.

13. The 6th Land Administration Domain Model (LADM) Workshop. https://wiki.tudelft.nl/bin/view/Research/ ISO19152/WorkshopAgenda2017 (last accessed on 26 August 2019).

14. Law no. $350 / 2001$ on spatial and urban planning (with subsequent amendments), Official Gazette no. 373, 10 July 2001.

15. http://www4.pmb.ro/wwwt/pug/pugs/TAB2001X.htm (last accessed on 6 September 2019)

16. http://www.pmb.ro/servicii/urbanism/pug/docs/ planul_UTR.pdf (last accessed on 6 September 2019)

17. https://doc.arcgis.com (last accessed on 9 September 2019).

18. https://nosplan.org/uncategorized/application-of-gisin-smart-cities/ (last accessed on 10 September 2019) 